\title{
A Study on the Culture Diet Development----A Case Study of Yimeng Mountain Area
}

\author{
Li SANG \\ School of liberal arts, Lin Yi University, Linyi 276005, China
}

\begin{abstract}
With its distinctive regional, ethnic and cultural history, Local food culture, which includes diet flavors, methods, manners, and the formation and development, has become an important component of a unique cultural resources and traditional folk culture. Viewed from the perspective of industrial economic development, local food culture tourism as tourism products an important part has been becoming an emerging tourist activities with broad market potential for development of tourism. As the research object, Yimeng diet culture and customs through the Yimeng people and local cuisine diet research, scientific summary and comprehensive grasp of the essence of Yimeng mountain food culture, to create a regional community in Yimeng food culture is unique and can be the starting point for the development of Yimeng food culture custom tourist card, can effectively expand the social and economic development of Linyi City and channels to promote the benefits of Linyi City tour operators to form a new growth point.
\end{abstract}

KEYWORD: Food; Custom; Economy; Tourism Development

\section{DIET CULTURE WITH TYPICAL REGIONAL CHARACTERISTICS OF YIMENG MOUNTAIN IN LINYI}

\subsection{Geographical distinctive, varied diet of Linyi}

With the rapid economic development of Yimeng Mountain, today, Linyi people has get rid of the humble status of diet for a long time, which is dry melon pancakes with green onions, sorghum, corn bread and pickles. Diet in the traditional practices shows diversified styles increasingly. Yimeng cuisine mainly has the following notable features, the category of daily pasta includes pancakes, grilled card, cake, pot pie, rice dumplings, rice cakes, cabbage pancake, corn bread, sponge cake, bread, rice, rolls, dumplings, Jianbao, ravioli and other blunt. The category of daily meat includes fish dishes, pork, dog, donkey, all the sheep, fried chicken, etc. Delicacies class has fungus, mushrooms, mushroom mountain, mountain fern, mountain onion, leek Hill, grasshopper, cicada, chrysalis, mountain scorpion, hare, pheasant, etc. There are daily soup and porridge, such as grits, rice, corn soup, salty confused, Valley scum soup, red bean foam, small tofu, bean curd, soybean milk, mutton soup. The category of diet has the collapse of traditional local food with rich local food color.

\subsection{Local cuisine with a wide impact in Linyi}

\subsubsection{Has the characteristics of traditional class snack food collapse}

Collapse eat snack foods are traditional Yimeng area. The original intent of " collapse" , is the fall or subsidence. " collapse ", the word in "collapse of food", can be understood as a verb which has a continuity, that is, by heating, appropriate dries within buns or pancakes wrapped dish of water filling.As a method of cooking food, there isn't this interpretation which can be regard as the unique of Yimeng people in the dictionary. There are two main kinds of collapsed food, which are collapsed pancake and collapsed buns. There are the same basic stuffing with smash of leeks, cabbage and shepherd, and the well mixture of some oil and salt depending on personal taste. When making, you should put the filling into the middle of the dough, spread evenly, then pancake folded into a rectangle, and then put it on the pan or griddle to cook and bake.

\subsubsection{Absorbing Confucian -style fish dish dishes in Linyi}

Linyi fish dish known in the late nineteenth and early twentieth century is an order of the Yi River, Shuhe River carp and altar inside ancestral temple as raw materials, a unique cooking technique from the 
processing of local dishes. Currently, fish dishes preserved are pot collapse fish, grapes fish, sweet and sour fish, lobster and fish Lake fish and so on.

\subsubsection{Poultry dishes with typical characteristics of Yimeng mountainous region}

(1) Monsanto bachelor chicken

During the dishes Fried Chicken founder Fuzeming opened shops in the city Mengyin Xiling, the dish was famous for cooked taste delicious, unique flavor which big cock. For fried chicken shop staff were men and food ingredients were for the year born male chicks, the dish named " chicken " and this shop is also known as "bachelor chicken shop." The dishes with Monsanto big cock for raw materials, with more than 30 kinds of Monsanto fine elegant spice, bright red color, wide Sauvignon juice, delicious full-bodied, fruity medicine, by the Linyi people and tourists alike. In 1995, the "bachelor chicken," the title of a registered trademark in the SAIC, and went out of Linyi. and set up a number of stores in Jinan, Beijing and other places.

(2) Feixian whole mutton soup

The dishes which are in fat but not greasy, not fishy smell of mutton and the soup is light, succulent and tender have become a popular favorite regional dishes of Linyi people. The dishes in Yimeng mountainous northern black goat is authentic, using Tuzao cauldron, spring water, firewood lamb, goat, sheep lung, Yang Du, mule, sheep, sheep's head, sheep hoof, sheep bones, and all in the pot cooking. In process, by adding Angelica, cloves, orange peel, cinnamon, strawberry, Amomum, cardamom, ginger, pepper and other spices deodorization to mention fresh, cook until nine mature, remove the sheep bones, lamb, offal, sheep blood and other chopped skillet, small open fire Serve. When serve, add salt, vinegar, monosodium glutamate, coriander, chili powder, pepper and other condiments depending on personal taste .Taste is very delicious and pure. Currently, there are more than 200 restaurants which are specially crafted Feixian whole mutton soup. There are also many restaurants Feixian whole mutton soup in Linyi, Jinan, Beijing and other places. Feixian whole mutton soup has been out of the county fee to the country.

(3) Panjia Lake dog in Linyi

Panjia Lake dog is made by the Yimeng mountain farm grass dog as raw materials. Panjia Lake dog with the color of fresh tender uses traditional techniques made carefully, which contains a lot of protein and trace elements such as calcium and phosphorus. According to legend Qianlong six down the south had four pass Yizhou Prefecture taste Panjia Lake dog and much appreciated. Now Panjia Lake dog to the State Trademark Office to apply for registration of a trademark Panjia Lake, 2005 by the title of the top ten Cuisines comment Linyi, Shandong and other snacks .

\section{(4) Junan Donkey}

Junan Donkey is regarded as a favorite regional dish, which holds any seasoning during cooking, eating only hot dipped salt chew slowly. The taste is very fragrant soft and mellow.

\subsubsection{The traditional cuisines of Linyi - grits and eight tempeh}

Eight tempeh and grits are Linyi traditional cuisines. Eight tempeh first appeared in the Qing Dynasty, as " the only vegetarian" original sauce, with large black beans, eggplant, fresh ginger, almonds, basil leaves, flowers, pepper, sesame oil and white wine brewing, therefore called "Eight treasures ." It with sophisticated, mellow sauce production has become well-known food and tourist gift of special gifts in Shandong Province. Grits are Linyi snacks. Everyone loved for its spicy and delicious, cold chills and stomach open. Drinking mix is Linyi morning tradition diet. In terms of writing, "grits " is made with meat soups, Western Muslim ancient legend of a breakfast food. Yuan Dynasty Dadu passed by a couple, which called "meat paste ", and later the imitators is more and more. Linyi County, grits is created by Linyi people in early Ming Dynasty. After evolution it gradually formed a unique style of Yizhou Cuisines including mix beef, lamb grits which are the most common, chicken grits which for Jane. Before the liberation, the grits of Linyi were most famous for beef grits of Yushan, chicken grits of Huang Jia and Liu Mazi. Now the grits of Linyi has been out Yimeng Mountain and has reputation in the field.

\section{YIMENG FOOD CULTURE CUSTOM HAS MULTI- FUNCTIONAL POTENTIAL OF THE TOURISM INDUSTRY IN THE CITY OF LINYI.}

\subsection{The possibility of Yimmeng food culture becoming an important part of the tourism industry}

Linyi is located in the Yimeng Mountain, by Yishan, Monsanto, and Lushan Mountains and near Zhongshan and other numerous low mountains, hills components. Mountain dense vegetation is the main base for the development of horticulture, animal husbandry. Hills are most widely distributed to the east of the Shuhe, large sandy soil, suitable for farming, peanuts, sweet potatoes, corn, tobacco and other crops in the main producing area. Plains include Yishu alluvial plains, the mountain valley plain and waterlogged lowland plains. Pro Tan plain soil deep, and soil fertility, is the main producing areas of grain and vegetables, known as the "granary " reputation. The mountain valley plain soil deep, moderate texture has variety of wheat, corn and 
other crops. Waterlogged lowland plains heavy clay soil, a variety of wheat, rice, vegetables and other crops. The entire area within the region distinctive, rich urban landscape, a wide variety of biological resources, agriculture, forestry, animal husbandry and fishery development with steady growth in business scale, which makes the food culture in this custom has long formed on the basis of environmental resources also have a typical Yimengshan regional characteristics, Which provides ample opportunities and possibilities for the exploitation of Linyi travel.

\subsection{Linyi City Yimeng food culture enrichment and development of tourism activities}

Linyi has long history, is one of the birthplaces of Chinese civilization, as far back as four, fifty million years ago, our ancestors created the ancient civilization in the land,5,000 years ago, where humans have mastered the winemaking techniques, Yimeng food culture is also gradually formed and developed based on the winemaking techniques. The unique flavors eat dishes of Yimeng area often accompanied by a long history and unique customs and traditions and customs processing technology, with strong local characteristics and profound cultural connotations. With Linyi City, relying on the unique advantages of river resources to Yihe axis, forming a development" of cross-strait development, group development," the pattern of urban construction and tourism circle surrounding Linyi City, Linyi local diet has become a new growth of various types of tourism projects point for the development of tourism in Linyi City brought new opportunities, but also on the Linyi City "cultural city" policy echoing Yimeng food culture has become a new custom business cards.

\section{THE STATUS AND PROBLEMS OF GOURMET TOURISM DEVELOPMENT IN LINYI}

\subsection{Propaganda is too small}

What learned from the relevant departments of Linyi City Tourism Bureau is that Linyi City has not put food and tourism of Yimeng with distinctive local characteristics as the basic structure of the overall tourism product. "Eating in Yimeng ", a brand with a rich cultural heritage, that propaganda is too small and the range is not affected, can not really attract more tourists to taste food products and assess food. And the publicity and promotion of food product and tourism of Yimeng still remain on several snacks and other traditional items.

\subsection{Brand awareness is not strong}

Linyi tourism diet lacks local diet which meet different levels of consumer groups require and different grades, and tourism brand awareness and innovative of food culture resource development.

\subsection{Operator quality is not high}

What found from a number of Linyi City Food Street research is that the quality of the operator's culture and business is generally low, lacking of knowledge level. The quality of health awareness for employee is not strong. There are often disorderly competitions between operators, which not form a joint force. Food industry is lack of the support of the person who has the theoretical knowledge and technical professionals. The development of the local food industry can not form scale.

\subsection{Lack of cultural charm}

In the development of the tourism industry, Yimeng local diet does not dig deep enough traditional food culture, only basically stay on the palate and not make visitors have a profound understanding to the local characteristics of Yimeng diet rich cultural heritage.

\section{DEVELOPMENT APPROACHES AND MEASURES OF FOOD TOURISM IN LINYI CITY}

\subsection{Carrying out research work Yimeng finishing diet culture and customs, and the establishment of Yimeng food culture heritage, reform and development mechanism.}

Relying on Linyi tourism Chief Network, Linyi History Office and Food Network Platform of Linyi, We should extensively collect, collate those data about Yimeng food culture materials, books. After that, we will compile the information into a tourism promotional book. On this basis, we summarize the characteristics of Yimeng mountain heritage community food culture, We should strive to tap and enhance Yimeng the essence of food culture, Adhere to elementary distributed to food Vernacularization to the text, then vegetables, Named by culture dishes, Interpretation of Culture with dishes, Continually tap the local food culture characteristics, In-depth analysis of the formation of Yimeng food culture resources, evolution, development, Various specialties cooked, nutritional characteristics and legends, allusions, and so on. By analyzing the attractiveness of local tourism resources and the development of the line, We should strive to build a complete diet Yimeng cultural heritage, reform and development mechanisms, In order to form a new concept in food culture resources Linyi public, then, 
on this basis, the adjustment of product structure of tourism, development of tourism resources in the diet has a strong local culture and content, For example, the government can organize a variety of local dishes in style propaganda points for Yimeng Food Festival, food culture city, food centers, Meanwhile, authorities can build market pattern set shopping and dining in one of the cultural fast food, casual dining, and many other formats coexist as part of a sightseeing tour of Linyi, In order to connect tourism, catering and entertainment, tourism, shopping, optimized Yimeng food culture environment, it has gradually become a new bright spot of tourism and economic growth around the city of Linyi tourism circle .

\subsection{To develop distinctive food culture brand products with Yimeng distinctive and to strengthen Yimeng food culture promotional work}

In order to produce a variety of styles of food culture Yimeng brand products, we shoud rely on the food processing enterprises of Linyi, and strive to develop Linyi local diet typical dishes, so that it will become an important tourist souvenirs and merchandise, so we gradually make traditional food and specialty diet products of Linyi region become industrialization, large-scale production. Gourmet tourism brand strategy can increase the cultural content of the diet products to stimulate tourist shopping desires, and enhance the attractiveness of tourism resources Yimeng diet, Further expand the tourism market, accelerate the spread of local food culture Strengthen the " eat in Yimeng," " gourmet Linyi " propaganda, For example, For example, we have to introduce people Yimeng food culture connotation and features as well as a variety of delicacies by way of a diversified, multi-level, multi-channel. In order to introduce people to the famous shops, famous attractions. We can increase the portion relating to tourism and catering guide map, tourist brochures, attractions specification. By strengthening the management of the restaurant industry, We can strengthen the management of the restaurant industry, to create a good environment Linyi food culture, and actively create Yimeng old brand. In addition, the target market, we have a choice to dietary and cultural resources Packaging Show. According to the preferences of tourists, we design, develop souvenirs, When we publicize Yimeng food culture, Let tasting food, learning cooking, explore the long history of Yimeng food culture gradually become a new tourist products and make it to the market, This will enhance the attractiveness of Yimeng diet cultural resources and create a diversified development pattern of Linyi tourism resources.

\subsection{Relying Linyi vocational and higher education platform for local food culture personnel professional training to improve the overall quality of the diet of local tourism practitioners.}

In recent years, Linyi municipal government continued to increase education funding and innnovation measures, so that vocational education and higher education has been growing rapidly in Linyi. In addition, Linyi first Vocational Education Group has now entered the preparatory phase. Yimeng mountain has its first comprehensive university. These have provided the conditions and accelerated the development of Yimeng education. On the basis of Vocational education and higher education in Linyi region, strengthen diet pre-service training of employees, Job training, Set Professional Food Culture, Food Culture opened compulsory and so on, we actively carry out cultural and educational tourism diet, let food culture or culinary student cultural connotation and the inherent quality of the promotion of education, these methods can effectively meet the needs of all levels of Linyi City tourism catering personnel.

In short, as political, economic and cultural center of Yi meng mountain area, and with its intelligent and industrious people, Linyi has formed a specific region food culture based on its given natural environment and human society in the south Shandong area.with the rapid economic development of Linyi region, especially in the National 117 urban civilization index evaluation in 2011, Linyi won the first national assessment, further expanding the visibility and reputation of Linyi City, which will promote the big development of the Linyi City's tourism, as an important part of tourism resources in Linyi City, Yimeng food culture tourism will also become a new economic growth point, and therefore fully tap the cultural connotation of the local diet Yimeng tourism product, increase efforts to develop tourism resources Linyi cuisine, Which has a very positive meaning for the promotion of local cultural and economic value, widening social and economic development of Linyi City, to achieve sustainable development of tourism.

\section{REFERENCES}

[1] Yia-In Lucy Chen. Alcohol consumption and health status in older middle-aged and elderly persons: Findings from a longitudinal national population health survey. University of Northern British Columbia (Canada), 2009.

[2] Xinye Zheng, Chu Wei, Ping Qin et al.. Characteristics of residential energy consumption in China: Findings from a household survey. Energy Policy, 2014. 